\title{
NBS
}

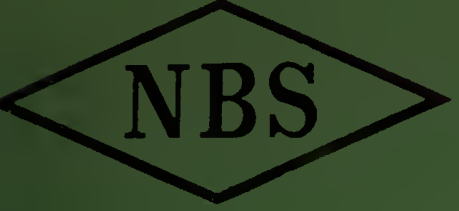

Eechnical Note No.132

Boulder Laboratories

EVALUATION OF CONVOLUTION INTEGRALS OCCURING IN THE THEORY OF MIXED PATH PROPAGATION

\author{
BY \\ J.R. JOHLER AND C.M. LILLEY \\ SCIENTIFIC REPORT NO. 14
}

Contract Title: Antenna Patterns in the Presence of Finite Ground Surfaces, CSO and A 58-40, dated March 31, 1958; Pro-61-568, dated February 2, 1961

Prepared for Electronics Research Directorate Air Force Cambridge Research Laboratories

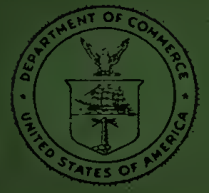

Office of Aerospace Research

United States Air Force

Bedford, Massachusetts

U. S. DEPARTMENT OF COMMERCE

NATIONAL BUREAU OF STANDARDS 


\section{THE NATIONAL BUREAU OF STANDARDS}

\section{Functions and Activities}

The functions of the National Bureau of Standards are set forth in the Act of Congress, March 3, 1901, as amended by Congress in Public Law 619, 1950. These include the development and maintenance of the national standards of measurement and the provision of means and methods for making measurements consistent with these standards; the determination of physical constants and properties of materials; the development of methods and instruments for testing materials, devices, and structures; advisory services to government agencies on scientific and technical problems; invention and development of devices to serve special needs of the Government; and the development of standard practices, codes, and specifications. The work includes basic and applied research, development, engineering, instrumentation, testing, evaluation, calibration services, and various consultation and information services. Research projects are also performed for other government agencies when the work relates to and supplements the basic program of the Bureau or when the Bureau's unique competence is required. The scope of activities is suggested by the listing of divisions and sections on the inside of the back cover.

\section{Publications}

The results of the Bureau's research are published either in the Bureau's own series of publications or in the journals of professional and scientific societies. The Bureau itself publishes three periodicals available from the Government Printing Office: The Journal of Research, published in four separate sections, presents complete scientific and technical papers; the Technical News Bulletin presents summary and preliminary reports on work in progress; and Basic Radio Propagation Predictions provides data for determining the best frequencies to use for radio communications throughout the world. There are also five series of nonperiodical publications: Monographs, Applied Mathematics Series, Handbooks, Miscellaneous Publications, and Technical Notes.

A completc listing of the Bureau's publications can be found in National Bureau of Standards Circular 460 , Publications of the National Bureau of Standards, 1901 to June 1947 (\$1.25), and the Supplement to National Bureau of Standards Circular 460, July 1947 to June 1957 (\$1.50), and Miscellaneous Publication 240, July 1957 to June 1960 (Includes 'ritles of Papcrs Publishod in Outside Journals 1950 to 1959) (\$2.25); available from the Superintendent of Documents, Government Printing Office, Washington 25, D. C. 
AFCRL- 994

Additional copies of this report are on sale by the U. S. Department of Commerce, Office of Technical Services, Washington 25, D. C. Agencies of the Department of Defense and their contractors may also direct requests to:

\author{
Armed Services Technical Information Agency \\ Documents Service Center \\ Arlington Hall Station \\ Arlington 12, Virginia
}

Department of Defense contractors must be established for ASTIA services or have their "need-to-know" certified by the cognizant military agency of their project and contract. 

NBS Project

Date of Report

$8300-11-83422$

October 15, 1961

AFCRL-994

EVALUATION OF CONVOLUTION INTEGRALS OCCURRING IN THE THEORY OF MIXED PATH PROPAGATION

by

J. R. Johler and C. M. Lilley

Scientific Report No. 14

Contract title: Antenna Patterns in the Presence of Finite

Ground Surfaces, CSO and A 58-40, dated March 31, 1958; Pro-61-568 dated February 2, 1961.

Prepared for

Electronics Research Directorate Air Force Cambridge Resear ch Laboratories

Office of Aerospace Research

United States Air Force

Bedford, Massachusetts

The research in this document has been sponsored by the Electronic Research Directorate of Air Force, Cambridge Research Laboratories, Office of Aerospace Research (USAF) Bedford, Massachusetts. The publication of this report does not necessarily constitute approval by the Air Force on the findings or conclusions contained herein. 



\section{NATIONAL BUREAU OF STANDARDS Eechnical Mote}

No. 132

\section{EVALUATION OF CONVOLUTION INTEGRALS OCCURRING IN THE THEORY OF MIXED PATH PROPAGATION}

by

J. R. Johler and C. M. Lilley

November 8, 1961

NBS Technical Notes are designed to supplement the Bureau's regular publications program. They provide a means for making available scientific data that are of transient or limited interest. Technical Notes may be listed or referred to in the open literature. They are for sale by the Office of Technical Services, U. S. Department of Commerce, Washington 25, D. C.

DISTRIBUTED BY

UNITED STATES DEPARTMENT OF COMMERCE

OFFICE OF TECHNICAL SERVICES

WASHINGTON 25, D. C.

Price $\$ 1.00$ 



\section{CONTENTS}

ABSTRACT . . . . . . . . . . . . . . . . . . . . . Page

1. Introduction . . . . . . . . . . . . . . . . . . . 1

2. Theory . . . . . . . . . . . . . . . . . . 2

3. Computations . . . . . . . . . . . . . . . . 13

4. Conclusions . . . . . . . . . . . . . . . . . . 13

REFERENCES . . . . . . . . . . . . . . . . . . . . 14 



\section{EVALUATION OF CONVOLUTION INTEGRALS OCCURRING IN THE THEORY OF MIXED PATH PROPAGATION}

\section{by}

\section{J. R. Johler and C. M. Lilley}

\section{ABSTRACT}

The theory of propagation of electromagnetic waves around a sphere treats the smooth homogeneous case, i.e., the case in which the surface impedance of the sphere is uninterrupted by an abrupt change in conductivity such as a land/sea boundary. It is known, however, that such a theory can be extended to treat inhomogeneous, irregular terrain by formulating certain convolution integrals which utilize the smooth homogeneous formulas. The evaluation of these integrals can be accomplished with dispatch on a large-scale electronic computer with the aid of numerical analysis techniques.

The particular case of a land/sea boundary in a smooth, spherical surface is illustrated for a variety of cases by evaluating the convolution integrals on a large-scale computer.

\section{Introduction.}

The theory of propagation of electromagnetic waves around a sphere usually assumes the earth to be smooth and homogeneous. However, some extensions of the theory have been developed by Monteath [1951] and Hufford [1952]. More recently, Bremmer [1954] developed the plane earth theory for abrupt conductivity changes and the procedure was established in detail for plane and spherical earth theory by Wait $[1956,1957,1961]$. The formulation of Wait [1961] also developed procedures for the cases of transmitting and receiving terminals at very great heights. Furutsu [1957] has also developed methods for evaluating the field over sections of inhomogeneous ground and in particular has developed a method especially convenient for electronic computer computations in which the length of the sections of inhomogeneous ground are large. 
The formulation of this problem by the above mentioned authors, especially Wait [1961], comprised convolution integrals involving an integrand which can be calculated with the Watson [1918] type series of residues. This paper demonstrates a method of evaluating these integrals by an application of numerical analysis technique.

Detailed numerical calculations for the particular case of the land/ sea boundary are presented.

\section{Theory.}

The analysis of the propagation over a finite surface can be more conveniently formulated from the smooth, homogeneous earth theory by utilizing the attenuation factor, F, directly instead of the field (vertical electric field, $\mathrm{E}_{\mathrm{r}}$, for example), where

$$
\mathrm{E}_{\mathrm{r}}=2 \mathrm{E}_{\mathrm{pr}} \mathrm{F}
$$

and the attenuation factor, $F$, is defined as the ratio of the total Hertz vector, $\Pi$ to the primary Hertz vector $\Pi_{\mathrm{pr}}$,

$$
F=F(\omega, d)=\pi / 2 \Pi_{p r}
$$

where the radiation field,

$$
\begin{aligned}
& E_{p r}=I_{o} \ell 10^{-7} \omega \exp \left(i \omega t-i k_{1} d\right) / d \\
& \Pi_{p r}=\exp \left(i \omega t-i k_{1} d\right) /\left(-i k_{1} d\right) .
\end{aligned}
$$

The factor, F, can be evaluated with the aid of the series of residues, [Bremmer, 1949], and in particular can be written, [Johler, Kellar and Walters, 1956],

$$
\begin{aligned}
& F=\left[2 \pi \alpha^{\frac{2}{3}}\left(k_{1} a\right)^{\frac{1}{3}} d / a\right]^{\frac{1}{2}} \sum_{s=0}^{\infty} \frac{f_{s}\left(h_{1}\right) f_{s}\left(h_{2}\right)}{\left[2 \tau_{s}-1 / \delta^{2}\right]} \\
& \times \exp \left\{-i\left[\left(k_{1} a\right)^{\frac{1}{3}} \tau_{s} \alpha^{\frac{2}{3}} \frac{d}{a}+\frac{\alpha d}{2 a}+\frac{\pi}{4}\right]\right\},
\end{aligned}
$$


where $\mathrm{t}=$ time, seconds, $\mathrm{a}$ is the radius of the spherical earth along which the vertical electric field, $E_{\mathbf{r}}$, is directed, $k_{1}$ is the wave number of air at the surface of the earth, $k_{1}=\omega \eta_{1} / c$ and $\eta_{1}$ is the index of refraction of air, $\eta_{1} \sim 1\left(c=2.997925^{(108)} \mathrm{m} / \mathrm{s}, \eta_{1} \sim 1.000338\right.$ at the surface). $\alpha$ is a factor which accounts for the vertical lapse of the index of refraction of air $\alpha \sim 0.75$ to $0.85 . h_{1}$ and $h_{2}$ are the heights of the transmitter and receiver respectively and $f_{s}(h), h=h_{1}, h_{2}$, are the height gain factor (identical for either receiver or transmitter as a result of reciprocity). The conductivity dielectric - constant parameter, $\delta=\delta_{\mathrm{e}}$ or $\delta=\delta_{\mathrm{m}}$ for vertical electric or vertical magnetic polarization of the Hertz dipole, respectively, can be written [Bremmer, 1949],

$$
\delta_{e}=\frac{-i \frac{k_{2}^{2}}{k_{1}^{2}} \alpha^{\frac{1}{3}}}{\left(k_{1} a\right)^{\frac{1}{3}}\left[\frac{k_{2}^{2}}{k_{1}^{2}}-1\right]^{\frac{1}{2}}},
$$

$$
\delta_{m}=\frac{k_{1}^{2}}{k_{2}^{2}} \delta_{e}
$$

The wave number of the ground can be written,

$$
k_{2}=\frac{\omega}{c} \sqrt{\epsilon_{2}-i \frac{\sigma \mu_{0} c^{2}}{\omega}}
$$


The residues of the series (5) are defined by the special roots, 'T ' of the differential equation of Riccati which has been formulated [Johler, Walters and Lilley, 1959]

$$
\frac{\mathrm{d} \delta}{\mathrm{d} \tau}-2 \delta^{2} \mathrm{~T}+1=0
$$

The height gain factors, $f_{s}(h)=f_{s}\left(h_{1}\right)$ or $f_{s}\left(h_{2}\right)$ are determined as the ratio of two Hankel functions, $\mathrm{H}_{\nu}{ }^{(2)}(\mathrm{z})$, [Bremmer, 1949],

$$
f_{s}(h)=\sqrt{\frac{a}{r}} \frac{H_{v_{s}}^{(2)}+\frac{1}{2}\left(k_{l} r\right)}{H_{v_{s}}^{(2)}+\frac{1}{2}\left(k_{l} a\right)}
$$

where

$$
r=a+h
$$

and

$$
v_{s} \sim k_{1} a+\left(k_{1} a\right)^{\frac{1}{3}} \tau_{s},
$$

which can be approximately written [Johler, Kellar and Walters, 1956] in terms of the tabulated Furry [1945] modified Hankel functions, $h_{2}(z)$

$$
f_{s}(h)=\frac{h_{2}\left\{\left(\frac{1}{2}\right)^{\frac{2}{3}}\left[\left(k_{1} a\right)^{\frac{2}{3}} \frac{2 h a^{\frac{1}{3}}}{a}-2 \tau_{s}\right]\right\}}{h_{2}\left\{-(2)^{\frac{1}{3}} \tau_{s}\right\}}
$$

provided $h<<$. 
The special case of a boundary (such as a land/sea boundary) located a distance, $d_{1}$, from the transmitter located on land with conductivity, $\sigma_{1}$ and dielectric constant $\epsilon_{2,1}$, or wave number of the ground, $\mathrm{k}_{2}$, is considered. A second finite ground surface located around the receiver from the distance $d_{1}$ to $d$ or the same boundary located a distance, $d_{2}$, from the receiver such that $d=d_{1}+d_{2}$ with a conductivity $\sigma_{2}$, a dielectric constant $\epsilon_{2,2^{\circ}}$. The field of the ground wave at the receiver is then, for a plane earth [Bremmer, 1949], and for a spherical earth [Wait, 1958, 1961],

$$
E_{r}=2 E_{p r} F^{(1,2)} \text {, }
$$

where

$$
\begin{aligned}
& F^{(l, 2)}=F^{(1,2)}(\omega, d) \text {, } \\
& F^{(1,2)}=F^{(1)}(d)-\sqrt{\frac{i k_{1} d}{2 \pi}}\left[\frac{z^{(2)}-Z^{(1)}}{Z_{0}}\right] \int_{0}^{d_{2}} \frac{F^{(1)}(d-\rho) F^{(2)}(\rho)}{d \rho} \\
& \left(d-d_{2}>0\right)
\end{aligned}
$$

where,

$$
z_{0}=\sqrt{\frac{\mu_{0}}{\epsilon_{0}}}=c \mu_{0} \sim 376.7
$$

ohms, the impedance of space, 
$\mathrm{k}_{1}=\frac{\omega}{\mathrm{c}} \eta_{1}$

$z^{(1)}=z_{0} \frac{k_{1}}{k_{2,1}} \sqrt{1-\frac{k_{1}^{2}}{k_{2,1}^{2}}}$,

$z^{(2)}=z_{0} \frac{k_{1}}{k_{2,2}} \sqrt{1-\frac{k_{1}^{2}}{k_{2,2}^{2}}}$.

$k_{2,1}=\frac{\omega}{c}\left[\epsilon_{2,1}-i \frac{\sigma_{1} \mu_{0} c^{2}}{\omega}\right]^{\frac{1}{2}}$

$k_{2,2}=\frac{\omega}{c}\left[\epsilon_{2,2}-i \frac{\sigma_{2}{ }^{\mu} o c^{2}}{\omega}\right]^{\frac{1}{2}}$,

$k_{2, p}=\frac{\omega}{c}\left[\epsilon_{2, p}-i \frac{{ }^{\sigma} p^{\mu}{ }_{o} c^{2}}{\omega}\right]^{\frac{1}{2}}$,

where the integer $\mathrm{p}$, identifies the particular finite surface under consideration. Thus, the smooth, homogeneous, spherical earthattenuation functions, $F^{(1)}(d)=F^{(1)}(\omega, d), F^{(1)}(d-\rho)=F^{(1)}(\omega, d-\rho)$, $F^{(2)}(\rho)=F^{(2)}(\omega, \rho)$ are employed in the calculation of the attenuation functions $F^{(1,2)}(\omega, d)$, for mixed propagation i.e., propagation over finite surfaces. The integral of the combination of the two attenuation functions $F^{(1)}(d-\rho) / \sqrt{d}-\rho$ and $F^{(2)}(\rho) / \sqrt{\rho}$ appearing inside the integral (15) is by convention called the convolution of these functions, i. e., $F_{1}^{*} F_{2}=\int_{0^{\prime}}^{t} F_{1}(t-\tau) F_{2}(\tau) d \tau$. 
An alternate form (of equation (15)), can be written,

$$
\begin{gathered}
F^{(1,2)}=F^{(2)}(d)-\sqrt{\frac{i k_{1} d}{2 \pi}}\left[\frac{z^{(1)}-z^{(2)}}{Z_{0}}\right] \int_{0}^{d_{1}} \frac{F^{(1)}(\rho) F^{(2)}(d-\rho)}{\sqrt{\rho(d-\rho)}} d \rho \\
\left(d>d_{1}\right)
\end{gathered}
$$

In either case, equations $(15,21)$, the problem is clearly resolved as the summation of the particular series of residues associated with the Watson [1918] transformation for the $F$, with various arguments function, $F^{(1)}(\rho), F^{(2)}(d), F^{(2)}(d-\rho)$; or $F^{(2)}(\rho), F^{(1)}(d), F^{(1)}(d-\rho)$, whichever is appropriate; and the evaluation of a finite integral between the limits 0 and $d_{1}$ or 0 and $d_{2}$, whichever is appropriate. This is accomplished quite readily with a Gaussian quadrature, [Kopal, 1955]

$$
\int_{0}^{d_{1,2}} f(\rho) d(\rho)=\sum_{m=1}^{M} w_{m} f\left(\rho_{m}\right)+\epsilon(M),
$$

where $\epsilon(M)$ is an error term which can be made arbitrarily small by increasing $M$, and,

$$
\begin{aligned}
& w_{m}=\frac{1}{2} d_{1,2} H_{m}, \quad m=1,2,3 \ldots M, \\
& \rho_{m}=\frac{1}{2} d_{1,2} x_{m}+\frac{1}{2} d_{1,2} .
\end{aligned}
$$


The $\mathrm{x}_{\mathrm{m}}{ }^{\prime} \mathrm{s}$ are the Gaussian abscissas, and $\mathrm{M}$ determines the number of values of the integrand to be used in the quadrature. The integral can be split into any number of finite integrals to get convergence,

$$
\int_{0}^{d_{1,2}} f(\rho) d \rho=\int_{0}^{a_{1}} f(\rho) d \rho+\int_{a_{1}}^{a_{2}} f(\rho) d \rho+\ldots+\int_{a_{n}}^{d_{1,2}} f(\rho) d \rho .
$$

The quadrature problem is therefore the evaluation of a finite integral,

$$
\int_{a}^{b} F(x) d x=\sum_{m=1}^{M} w_{m} F\left(x_{m}\right)+\epsilon(M) .
$$

where,

$$
x_{m}=\frac{1}{2}\left[(b-a) x_{m}+(b+a)\right]
$$

The Gaussian weights and abscissas can be determined from the following:

$$
\begin{aligned}
& \int_{-1}^{1} f(x) d x=\sum_{m=1}^{M} H_{m} f\left(x_{m}\right), \\
& W_{m}=\frac{1}{2}(b-a) H_{m} .
\end{aligned}
$$


The $\mathrm{x}_{\mathrm{m}}$ 's are the roots of the Legendre polynomials defined by,

$$
\begin{aligned}
& \frac{d^{m}}{d^{x^{m}}}\left(x^{2}-1\right)^{m}=2 m_{m !} P_{m}(x), \\
& P_{0}(x)=1 \\
& P_{1}(x)=x \\
& P_{2}(x)=\frac{3}{2} x^{2}-\frac{1}{2} \\
& \cdots, \text { and } \\
& (m+1) P_{m+1}(x)+m P_{m-1}(x)=(2 m+1) x P_{m}(x) .
\end{aligned}
$$

Upon determination of the roots, the weight coefficients, $\mathrm{H}_{\mathrm{m}}$, of the corresponding quadrature formulas are evalua ted as follows:

$$
H_{m}=\frac{2}{\left(1-x_{m}^{2}\right)\left[P_{m}^{\prime}\left(x_{m}\right)\right]^{2}}
$$

Forty-eight Gaussian weights and abscissas were used in the functions graphed in this paper, convergence being obtained by increasing the number of intervals of integration. These weights and abscissas have been published by Kopal [1955], Davis and Rabinowitz [1956].

The singularity, equation (21) for example,

$$
[\rho(d-\rho)]^{-\frac{1}{2}}=\left[d\left(d-d_{1}\right)\right]^{-\frac{1}{2}},\left(d=d_{1}\right) \text {, }
$$

would apparently present some difficulties in numerical integration. 
However, it should be noted that the Gaussian quadrature, equations $(24,25,26)$ does not include the end points of the interval of integration. A loss of precision, however, could possibly occur, but this could be sidestepped by the use of multiple precision. In any case, this did not become a problem for the examples presented in this paper.

The Gaussian quadrature techniques do not utilize the values of the integrand $(15,21)$ at the end points of integration. However, close to zero the series of residues, equation (5), converges slowly and, hence, the calculation of the attenuation function, $F$, becomes more difficult with a considerable reduction in computation efficiency. Since the Gaussian points, $x_{m}$, tend to cluster, equation (24) tends to cluster in the vicinity of $d_{1,2}=0$, it is desirable to utilize the plane earth approximation in this area. Indeed, quite high precision can be obtained if the computation is preferred both by the series of residues and the plane-earth theory such that a comparison is made in the transition region to ascertain the computation precision. The attenuation for the plane earth theory [Norton, 1937] is,

$$
\begin{aligned}
F= & \frac{2}{\sqrt{d^{2}+h^{2}}} i^{2} \sin ^{2} \tau\left(1+R_{e}\right)+\left(1-R_{e}\right)\left[1-\frac{k_{1}^{2}}{k_{1}^{2}}+\frac{k_{1}^{4}}{k_{1}^{4}} \sin \tau\right] f(\rho) \\
& \left.-2\left[\frac{k_{1}}{k_{2}} \sqrt{1-\frac{k_{1}^{2}}{k_{2}^{2}}} \sin \tau\right] \cos \tau\right\},
\end{aligned}
$$


where,

$$
f(\rho)=1-i \sqrt{\pi \rho} \exp (-\rho) \operatorname{erfc}(i \sqrt{\rho})
$$

if,

$$
\rho_{1}=\frac{i k_{1} D}{2} \frac{k_{1}^{2}}{k_{2}^{2}}\left[1-\frac{k_{1}^{2}}{k_{1}^{2}} \sin r\right],
$$

where

$$
D=\sqrt{d^{2}+h^{2}},
$$

then,

$$
\rho=\rho_{1}\left\{1+\frac{h}{R_{e \frac{1}{k_{2}}} \sqrt{1-\frac{k_{1}^{2}}{k_{2}^{2}}}}\right\}
$$

where $h_{1}$ is the height of either the transmitter, $h=h_{1}$ or the receiver, $h=h_{2}$ and $k_{1}$ and $k_{2}$ are the wave numbers of the medium previously defined, equation $(18,19,20)$, which can be specified as some finite surface, $k_{2, p}$. The factor $R_{e}$ is the Fresnel reflection coefficient for vertical polarization,

$$
\begin{aligned}
R_{e}= & R_{e}(\tau)=\left\{k_{2}{ }^{2} \cos \tau / k_{1}{ }^{2}-\left[k_{2}{ }^{2}-\sin \tau\right]^{\frac{1}{2}}\right\} /\left\{k_{2}{ }^{2} \cos \tau / k_{1}{ }^{2}\right. \\
& \left.+\left[k_{2}{ }^{2} / k_{1}{ }^{2}-\sin ^{2} \tau\right]^{\frac{1}{2}}\right\}
\end{aligned}
$$


where $T=\tan ^{-1}(d / h)$. Thus, the height gain previously discussed for the residue series, equation $(10,12)$, is built into the plane-earth theory for short distances. It is now possible, with the aid of the convolution integrals $(15,21)$, to elevate transmitting and/or receiving dipoles and evaluate the field over mixed ground transmissions. Indeed, in the limit whereupon the receiver or transmitter is elevated to several earth radii; equation (10), the antenna pattern over mixed ground, is described. Furthermore, the convolution integrals can be developed for three or more finite ground surfaces [Wait, 1961]. Thus, discontinuities located at distances, $d_{1}, d_{1}+d_{2}$ from the transmitter or $d=d_{2}+d_{3}$ and $d-d_{3}$ respectively from the receiver, where $d=d_{1}+d_{2}+d_{3}$ can be written,

$$
\begin{aligned}
& F^{(1,2,3)}=F^{(1)}-\sqrt{\frac{i k_{1} d}{2 \pi}}\left[\frac{z^{(2)}-z^{(3)}}{z_{0}}\right] \int_{d_{1}+d_{2}}^{d} \frac{\left.F^{(1)}(\rho) F^{(3)} d-\rho\right)}{\sqrt{\rho(d-\rho)}} d \rho \\
& -\sqrt{\frac{i k d}{2 \pi}}\left[\frac{z^{(2)}-z^{(1)}}{z_{o}}\right] \int_{d_{1}}^{d_{1}+d_{2}} \frac{F^{(1)}(\rho)}{\sqrt{\rho}}\left[\frac{F^{(2)}(d-\rho)}{\sqrt{d-\rho}}\right.
\end{aligned}
$$$$
\left.-\sqrt{\frac{i k_{1} d}{2 \pi}} \int_{d_{1}+d_{2}}^{d} \frac{F^{(2)}(\eta-\rho) F^{(3)}(d-\eta)}{\sqrt{(\eta-\rho)(d-\eta)}} d \eta\right] d \rho .
$$ 


\section{Computations.}

The results of computations to illustrate technique are presented in figures $1,2,3,4$. The amplitude, figures 1,2 illustrate the recovery effect of a land/sea boundary noted by Millington [1949]. There is, of course, a corresponding phase recovery, figures 3,4. These computations were carried out on the CDC-1604 computer.

\section{Conclusions.}

The results of this investigation indicate that the problem of wave propagation over inhomogeneous or finite ground surfaces can be treated with comparative ease on a large scale computer with the aid of numerical analysis techniques applied to the convolution integrals and an adequate technique for summing the series of residues.

\section{Acknowledgments.}

The series of residues and the ground wave computer program concept was developed by John D. Harper, Jr. and J. R. Johler of Division 85.10 (Applied Electromagnetic Theory Section) and Harper programed same for IBM-704 and CDC-1604 computers. The convolution integrals were programed for CDC-1604 by C. M. Lilley of the same group. 


\section{REFERENCES}

Bremmer, H., Terrestrial radio waves; theory of propagation, Elsevier Publ. Co., New York, New York, (1949).

Bremmer, H., The extension of Sommerfeld's formula for the propagation of radio waves over a flat earth to different conductivities of the soil, Physical XX, 44l460 , (1954).

Davis, P., P. Rabinowitz, Abscissas and weights for Gaussian quadratures of high order, NBS, J. of Research paper 2645, 35-37, (1956).

Furutsu, K. , J. of Radio Research Lab. (Japan) Vol. 2, No. 10, eq. (7-1) (1955). See also Vol. 4, No. 16, No. 18, (1957).

Hufford, G. A., An integral equation approach to the problem of wave propagation over an irregular surface, Qunt. Appl. Math., 9, 391, (1952).

Johler, J.R., W. J. Kellar and L. C. Walters, Phase of the low radio frequency ground wave, NBS Circular 573, U.S. Govt. Printing Office, Washington, D. C. (June 27, 1956).

Johler, J.R., L. C. W alters and C. M. Lilley, Low- and very low - radio frequency tables of ground wave parameters for the spherical earth theory. The roots of Riccati's differential equation, NBS Tech. Note, No. 7, PB151366, U.S. Dept. of Commerce, Office of Tech. Services, Washington 25, D. C. , (Feb. 1, 1959).

Johler, J.R., L. C. Walters, C. M. Lilley, Amplitude and phase of the low - and very low - radio frequency ground wave, NBS Tech. Note, No. 60, PBl61561, U. S. Dept. of Commerce, Office of Tech. Services, Washington 25, D. C. , (June 1, 1960). 
Kopal, Z., Numerical analysis, John Wiley and Sons, Inc. , New York, New York, p. 367, (1955).

Millington, G., Ground-wave propagation across a land/ sea boundary, Nature, 164, 114-45 (July, 1949), 163 , 128, (June 1949).

Millington, G., Ground-wave propagation over an inhomogeneous smooth earth, Inst. of Elec. Eng., Proc. III 96, 53-64, (1949).

Monteath, G. D. , Application of the compensation theorem to certain radiation and propagation problems, Inst. of Radio Eng., London, Proc., 98, Part IV, 1-8, (1951).

Norton, K. A., The propagation of radio waves over the surface of the earth and in the upper atmosphere, Part II, Proc. Inst. of Radio Eng., No. 9, 25, (Sept. 1937).

Wait, J. R., Mixed paths ground-wave propagation, short distances, J. or Research of NBS, 57, No. 1, Research paper 1687, 1-15, (July 1956).

Wait, J. R. and J. Householder, Mixed-path waves propagation, 2 layer distances, J. or Research of NBS, 59, No. 1, 19-26, (July 1957).

Wait, J. R., On the theory of mixed-path, ground-wave propagation on a spherical earth, J. of Research of NBS, 65D, No. 4, (July-Aug. 1961).

Wait, J. R., On the theory of propagation of electromagnetic waves along a curved inhomogeneous surface, Can. J. Phys. 36, pp. 9-17, (Jan. 1958).

Watson, G. N., The diffraction of electric waves by the earth, Proc. Roy. Soc., London, 95, p. 83, (1918-19). 


\section{LIST OF FIGURES}

PAGE

Fig. 1 Amplitude of the ground wave as a function of distance for a variety of land/sea boundary locations, $d_{1}$, illustrating the recovery effect, $\mathrm{f}=1000 \mathrm{kc} / \mathrm{s}$.

Fig. 2 Amplitude of the ground wave as a function of distance for a variety of land/sea boundary locations, $d$, illustrating the recovery effect, $\mathrm{f}=3000 \mathrm{kc} / \mathrm{s}$, noted by Millington.

Fig. 3 Phase of the ground wave as a function of distance for a variety of land/sea boundary locations, $d_{1}$, illustrating the recovery effect, $f=1000 \mathrm{kc} / \mathrm{s}$.

Fig. 4 Phase of the ground wave as a function of distance for a variety of land/sea boundary locations, $d_{1}$, illustrating the recovery effect, $f=3000 \mathrm{kc} / \mathrm{s}$. 


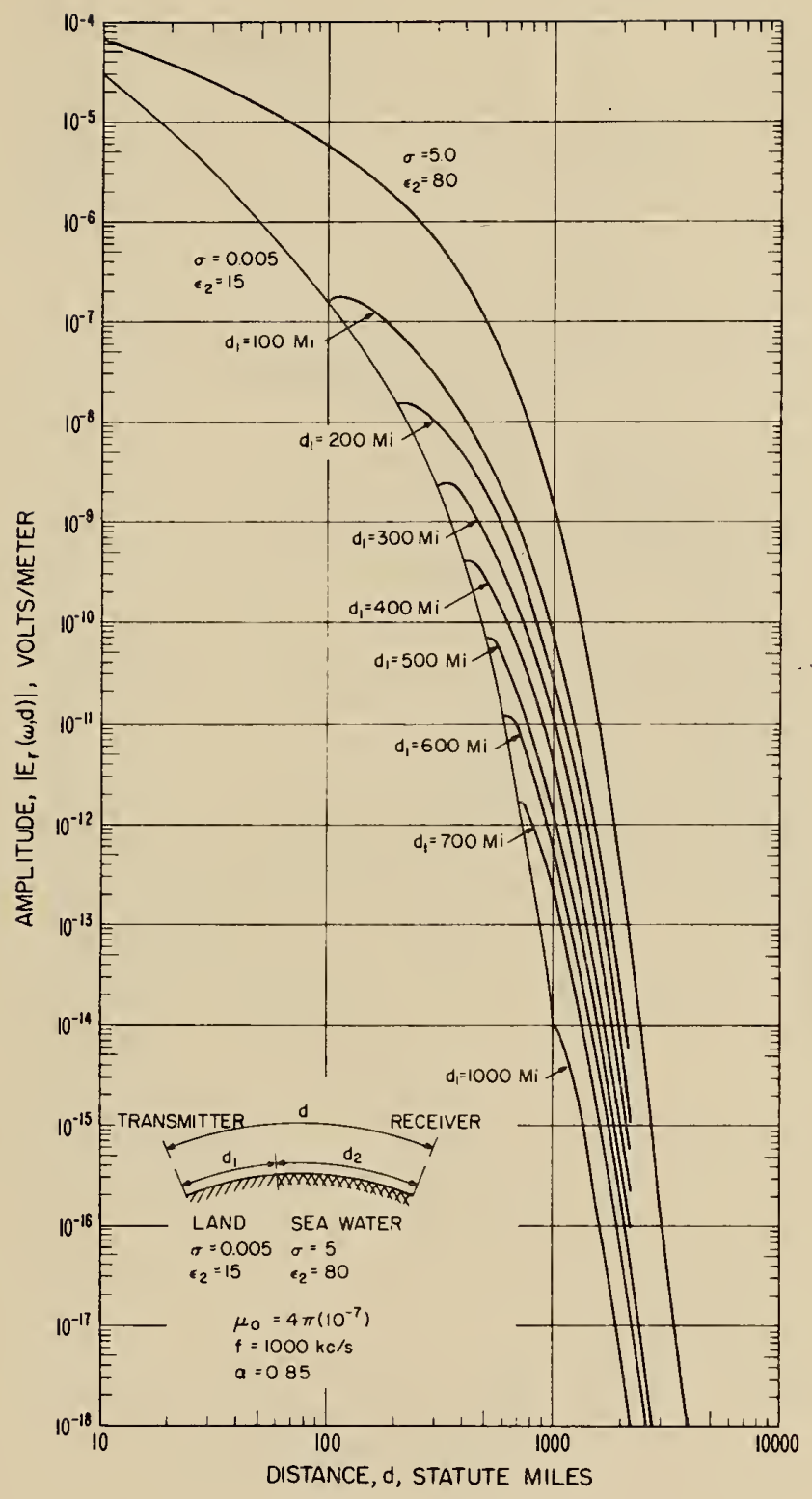

Figure 1. Amplitude of the ground wave as a function of distance for a variety of land/sea boundary locations, $a_{1}$, illustrating the recovery effect, $f=1000 \mathrm{kc} / \mathrm{s}$. 


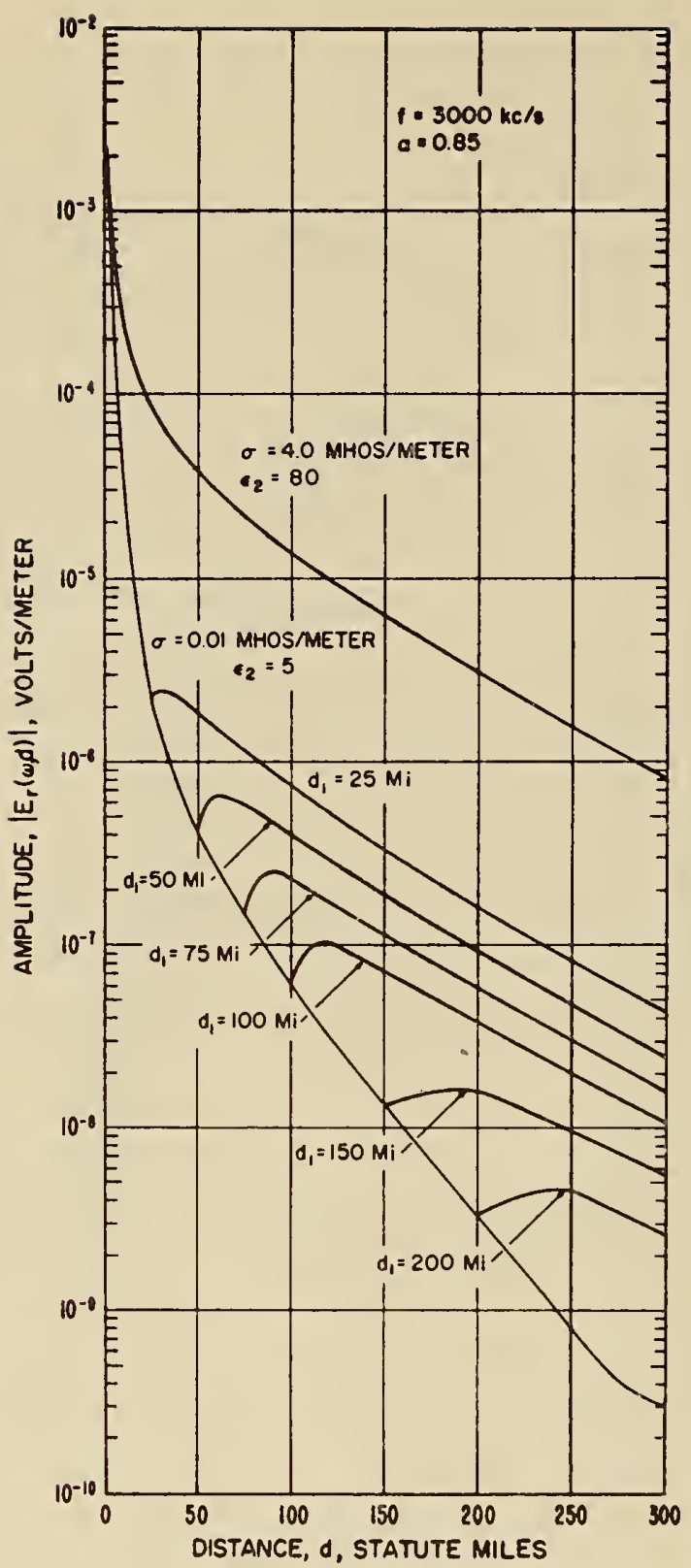

Figure 2. Amplitude of the ground wave as a function of distance for a variety of land/sea boundary locations, $d_{1}$, illustrating the recovery effect, $f=3000 \mathrm{kc} / \mathrm{s}$, noted by Millington. 


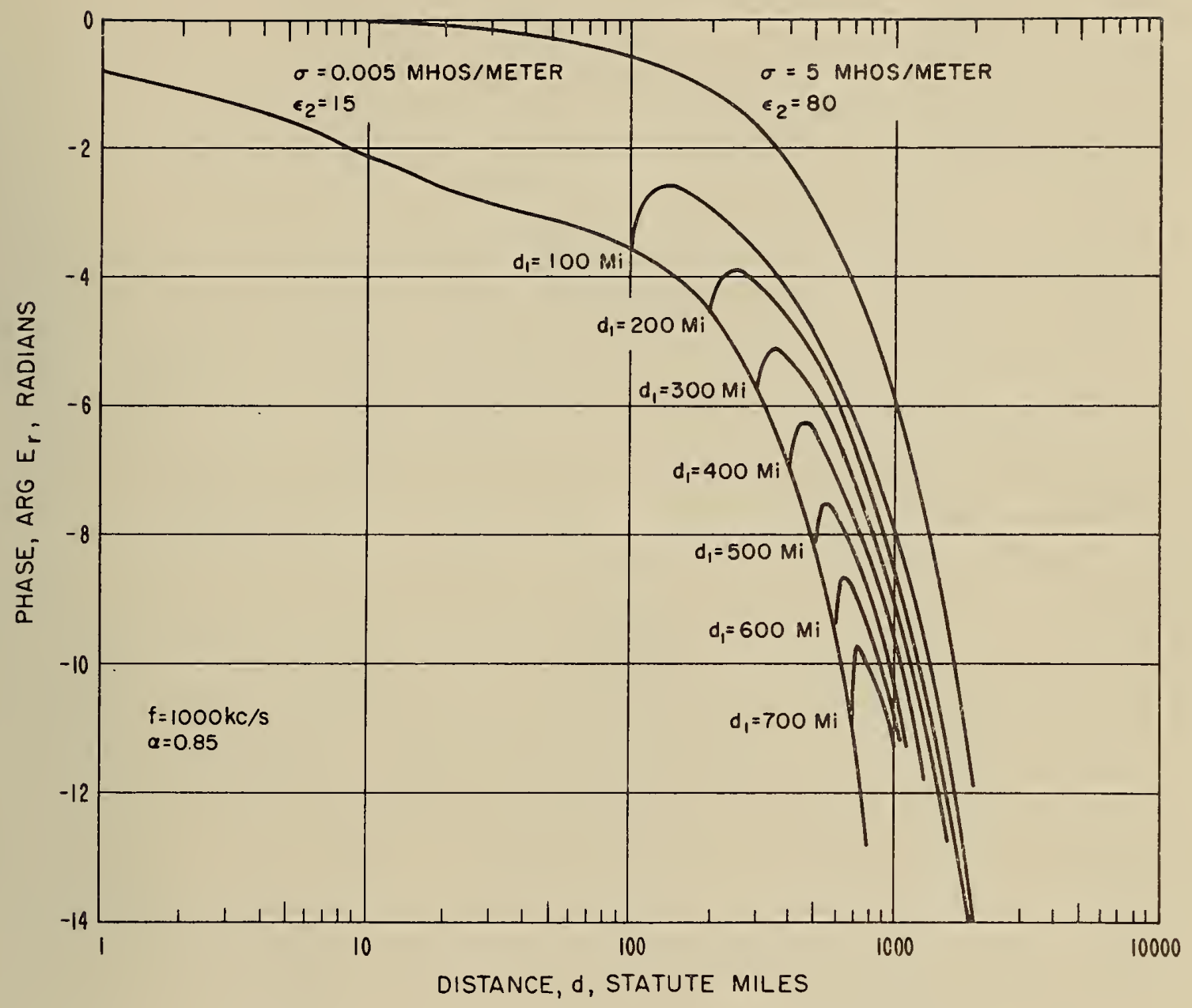

Figure 3. Phase of the ground wave as a function of distance for a variety of land/sea boundary locations, $d_{1}$, illustrating the recovery effect, $f=1000 \mathrm{kc} / \mathrm{s}$. 


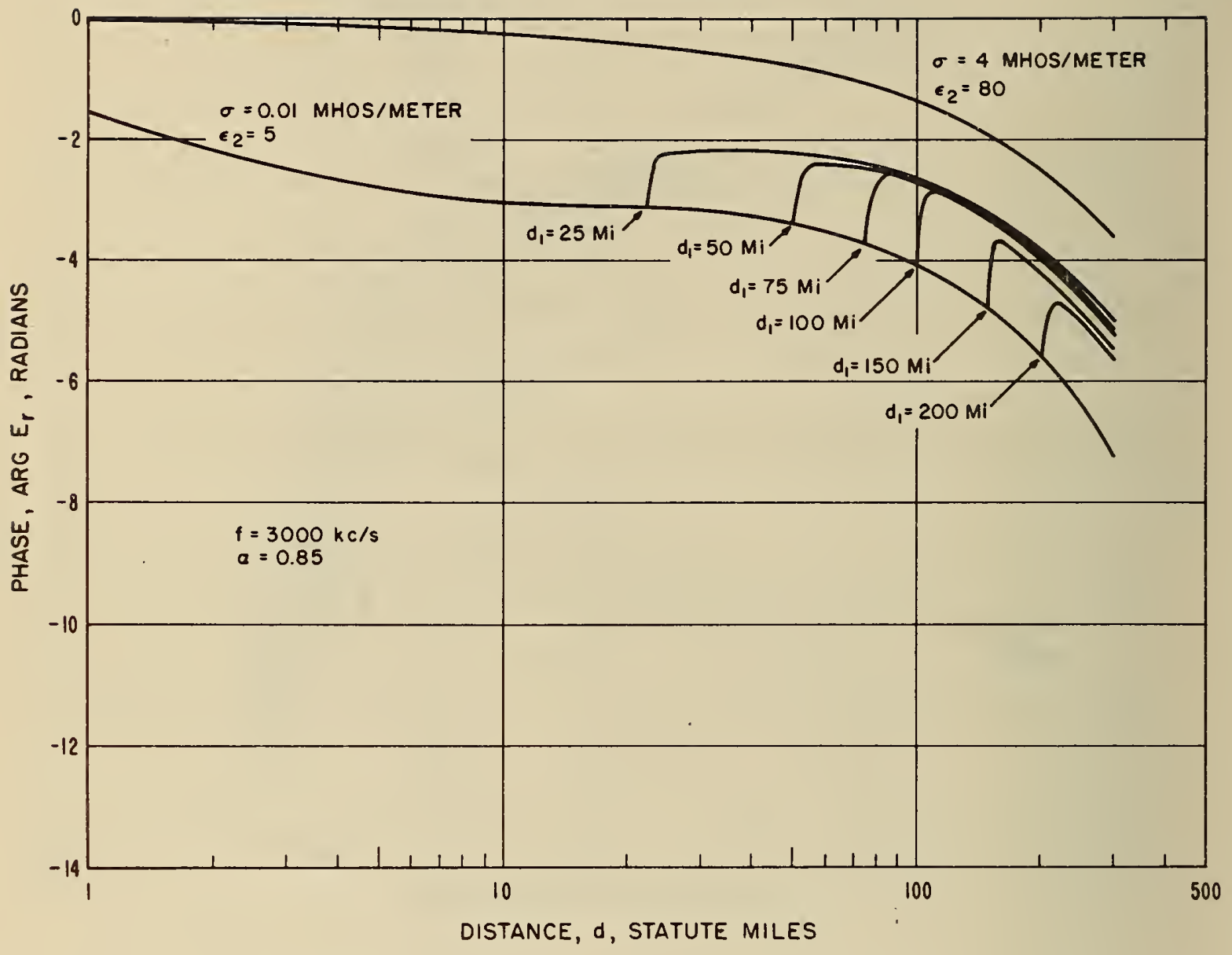

Figure 4. Phase of the ground wave as a function of distance for a variety of land/sea boundary locations, $d_{l}$, illustrating the recovery effect, $f=3000 \mathrm{kc} / \mathrm{s}$. 


\section{THE NATIONAL BUREAU OF STANDARDS}

Tize scope of activities of the National Bureau of Standards at its major laboratories in Washington, D.C., and Boulder, Colorado, is suggested in the following listing of the divisions and sectionsengaged in technical work. In reneral, each section carries out specialized research, development, and engineering in the field indicated by is title. A brief description of the activities, and of the resultant publications, appears on the inside of the froht cover.

\section{ISHINGTON, D.C.}

Flectricity. Resistance and Reactance. Electrochemistry. Electrical Instruments. Magnetic Measurements. Dielectrics.

Metrology. Photometry and Colorimetry. Refractometry. Photographic Research. Length. Engineering Metrology. Mass and Scale. Volumetry and Densimetry.

lleat. Temperature Physics. Heat Measurements. Cryogenic Physics. Equation of State. Statistical Physics. Radiation Physics. X-ray. Radioactivity. Radiation Theory. High Energy Radiation. Radiological Equipment. Nucleonic Instrumentation. Neutron Physics.

Analytical and Inorganic Chemistry. Pure Substances. Spectrochemistry. Solution Chemistry. Standard Reference Materials. Applied Analytical Research.

Mechanics. Sound. Pressure and Vacuum. Fluid Mechanics. Engineering Mechanics. Rheology. Combustion Controls.

Organic and Fibrous Materials. Rubber. Textiles. Paper. Leather. Testing and Specifications. Polymer Structure. Plastics. Dental Research.

Metallurgy. Thermal Metallurgy. Chemical Metallurgy. Mechanical Metallurgy. Corrosion. Metal Physics. Electrolysis and Metal Deposition.

Mineral Products. Engineering Ceramics. Class. Refractories. Enameled Metals. Crystal Growth. Physical Properties. Constitution and Microstructure.

Building Research. Structural Engineering. Fire Research. Mechanical Systems. Organic Building Materials. Codes and Safety Standards. Heat Transfer. Inorganic Building Materials.

Applied Mathematics. Numerical Analysis. Computation. Statistical Engineering. Mathematical Physics. Operations Research.

Data Processing Systems. Components and Techniques. Digital Circuitry. Digital Systems. Analog Systems. Applications Engineering.

Atomic Physics. Spectroscopy. Infrared Spectroscopy. Solid State Physics. Electron Physics. Atomic Physics. Instrumentation. Engineering Electronics. Electron Devices. Electronic Instrumentation. Mechanical Instruments. Basic Instrumentation.

Physical Chemistry. Thermochemistry. Surface Chemistry. Organic Chemistry. Molecular Spectroscopy. Molecular Kinetics. Mass Spectrometry.

Office of Weights and Measures.

\section{BOULDER, COLO.}

Cryogenic Engineering. Cryogenic Equipment. Cryogenic Processes. Properties of Materials. Cryogenic Technical Services.

lonosphere Research and Propagation. Low Frequency and Very Low Frequency Research. Ionosphere Research. Prediction Services. Sun-Earth Relationships. Field Engineering. Radio Warning Services.

Radio Propagation Engineering. Data Reduction Instrumentation. Radio Noise. Tropospheric Measurements. Tropospheric Analysis. Propagation-Terrain Effects. Radio-M!eteorology. Lower Atmosphere Physics.

Radio Standards. High Frequency Electrical Standards. Radio Broadcast Service. Radio and Microwave Materials. Atomic Frequency and Time Interval Standards. Electronic Calibration Center. Millimeter-Wave Research. Vicrowave Circuit Standards.

Radio Systems. High Frequency and Very High Frequency Research. Modulation Research. Antenna Research. Navigation Systems.

Upper Atmosphere and Space Physics. Upper Atmosphere and Plasma Physics. Ionosphere and Exosphere Scatter. Airglow and Aurora. Ionospheric Radio Astronomy. 


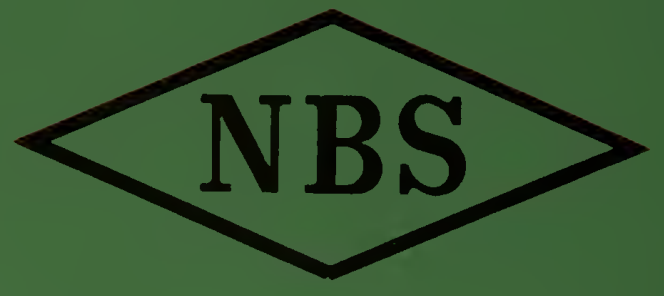

